\title{
Reply to Letter Regarding "The Value of Rotational Venography Versus Anterior-Posterior Venography in 100 Consecutive IVC Filter Retrievals"
}

\author{
S. William Stavropoulos ${ }^{1} \cdot$ Scott O. $_{\text {Trerotola }}{ }^{1} \cdot$ Ryan M. $_{\text {Kiefer }}{ }^{1}$ (D)
}

Received: 2 December 2015/Accepted: 6 December 2015/Published online: 24 December 2015

(C) Springer Science+Business Media New York and the Cardiovascular and Interventional Radiological Society of Europe (CIRSE) 2015

To the editor,

We appreciate the interest of Jia et al. in our article "The Value of Rotational Venography Versus Anterior-Posterior Venography in 100 Consecutive IVC Filter Retrievals" [1]. Because this was not a surgical or necropsy-based study, an embedded filter tip was defined in our study by a composite reference of the standard imaging definition of lack of contrast around the filter tip along with the operative findings encountered during filter removal that required removal with endobronchial forceps. We feel this is a far more accurate definition compared with the time- and tiltbased definition proposed by the authors of the letter. Further, we prefer an evidence-based definition to a conjectural one. It has been elegantly shown that filter components can become embedded within 30 days [2] and likely sooner, given that the process of development of intimal hyperplasia in foreign bodies such as stents and filters begins immediately; one recent study of coronary stents showed $>90 \%$ strut coverage by 2 weeks [3]. The authors of the letter suggest, without any evidentiary basis, that 15 days is the minimum time needed to have a tip embedded filter. Given that there are no data to support this time-based definition, coupled with evidence in the literature to the contrary, their assertion that a filter removed at 11 days cannot be tip embedded is untenable.

We thank Jia et al. for their interest in our work and appreciate the opportunity to further discuss the issue they

S. William Stavropoulos

stav@uphs.upenn.edu

1 Division of Interventional Radiology, Department of Radiology, Hospital of University of Pennsylvania Medical Center, 1 Silverstein, 3400 Spruce St., Philadelphia, PA 19104, USA raised. The issue raised by their letter, however, is not central to the importance of this study. The mean dwell time for filters in our study was 448 days and only 1 was removed at 11 days. Rotational venography can help interventionalists plan an appropriate approach to filter removal and avoid unsuccessful attempts to remove tipembedded filters using standard techniques which can occur if only AP venography is used. We stand by the conclusion of our study that "rotational venograms allow for more accurate detection of tip-embedded IVC filters compared to AP views alone."

Sincerely,

S. William Stavropoulos, MD

Scott O. Trerotola, MD

Ryan M. Kiefer

Disclosure Dr. Stavropoulos has nothing to disclose. Dr. Trerotola has nothing to disclose. Ryan Kiefer has nothing to disclose.

\section{References}

1. Kiefer RM, Pandey N, Trerotola SO, Nadolski GJ, Stavropoulos $\mathrm{SW}$. The value of rotational venography versus anterior-posterior venography in 100 consecutive IVC filter retrievals. Cardiovasc Intervent Radiol. 2015. doi:10.1007/s00270-015-1183-3.

2. Laborda A, Lostale F, Rodriguez, et al. Laparoscopic demonstration of vena cava wall penetration by inferior vena cava filters in an ovine model. J Vasc Interv Radiol. 2011;22:851-6.

3. Nishio R, Shinke T, Morino Y. Early phase arterial reaction following drug-eluting and bare-metal stent implantation in patients with ST-segment elevation myocardial infarction. Int Heart J. 2015;56:389-94. 